\title{
Impact of a theoretically based sex education programme (SHARE) delivered by teachers on NHS registered conceptions and terminations: final results of cluster randomised trial
}

\author{
M Henderson, D Wight, G M Raab, C Abraham, A Parkes, S Scott, G Hart
}

\begin{abstract}
Objective To assess the impact of a theoretically based sex education programme (SHARE) delivered by teachers compared with conventional education in terms of conceptions and terminations registered by the NHS.

Design Follow-up of cluster randomised trial 4.5 years after intervention.

Setting NHS records of women who had attended 25 secondary schools in east Scotland.

Participants 4196 women (99.5\% of those eligible). Intervention SHARE programme (intervention group) $v$ existing sex education (control group).

Main outcome measure NHS recorded conceptions and terminations for the achieved sample linked at age 20 .

Results In an "intention to treat" analysis there were no significant differences between the groups in registered conceptions per 1000 pupils (300 SHARE $v 274$ control; difference $26,95 \%$ confidence interval -33 to 86 ) and terminations per 1000 pupils (127 $v$ 112; difference $15,-13$ to 42) between ages 16 and 20.

Conclusions This specially designed sex education programme did not reduce conceptions or terminations by age 20 compared with conventional provision. The lack of effect was not due to quality of delivery. Enhancing teacher led school sex education beyond conventional provision in eastern Scotland is unlikely to reduce terminations in teenagers.

Trial registration ISRCTN48719575.
\end{abstract}

\section{Introduction}

Worldwide, young people are at risk of unwanted pregnancies, ${ }^{1}{ }^{2}$ sexually transmitted diseases, and unsatisfactory ${ }^{3}$ or coerced ${ }^{4}$ early sexual relationships. Sexual health services help to improve sexual health in young people, ${ }^{56}$ but school sex education is regarded as the most effective way of targeting this group. ${ }^{78}$

Several overviews have concluded that sex education can have beneficial effects on sexual behaviour, ${ }^{6}{ }^{10}$ although the earlier reviews relied almost entirely on quasi-experimental studies rather than randomised trials. Generally, the more rigorous evaluations of school sex education have been less likely to find positive outcomes. ${ }^{11}$ The only review restricted to randomised trials concluded that primary prevention strategies did not delay sexual intercourse, improve use of contraceptives, or reduce pregnancies. ${ }^{12}$ Furthermore, experimental evaluations often have considerable attrition from the intended target group or rely on self reported behavioural outcomes, or both, which has potential for presentational bias. ${ }^{12}$ We are aware of only one published randomised trial of school sex education that uses anything other than self reported data to evaluate effectiveness. In a programme recommending abstinence at a girls' high school in Chile, researchers used clinical data on pregnancies to show that the intervention reduced conceptions over four years. ${ }^{13}$ While these results are encouraging, they assume that any pregnancies that were terminated (which was illegal) were balanced across the groups in the trial.

Between 1993 and 1996 a sex education programme delivered by teachers (SHARE) was developed for 13-15 year olds in Scotland; this was evaluated between 1996 and 1999 in a cluster randomised trial. Interim outcomes at six months after the intervention (average age 16 years 1 month) showed that, compared with those receiving conventional sex education, SHARE improved knowledge and the quality of sexual relationships but had no impact on reported sexual or contraceptive behaviour. $^{14}{ }^{15}$ At this age, however, only a third of the sample reported having sexual intercourse and follow-up data were obtained from only $70 \%$ of the original sample.

We report on the impact of the intervention on conceptions and terminations by age 20 (4.5 years after the intervention) as recorded by the NHS. By linking to NHS data for the whole cohort of young women we have outcomes that are not subject to reporting biases and much less affected by sample attrition than outcomes from self reported data.

\section{Methods}

The intervention programme

The SHARE (sexual health and relationships) programme was developed and piloted in Scotland over three years in consultation with teachers, sex education specialists, and education and health promotion departments. ${ }^{16}$ It is a five day training programme for teachers plus a 20 session pack: 10 sessions in the third year of secondary school (at ages 13-14) and 10 in the fourth year (at ages 14-15). ${ }^{17}$ It is intended to reduce unwanted pregnancies, reduce unsafe sex, and improve the quality of sexual relationships. The total cost of training each teacher was about $£ 900$ (€1343,\$1684), including a copy of the package.

The sociopsychological and sociological theoretical basis of the programme has been set out previously. ${ }^{18}$ The programme combines active learning (such as small group work and games), information leaflets on sexual health, and the development of

Further details on the final outcomes of the SHARE programme can be found bmj.com. 
skills to negotiate sexual encounters, handle condoms, and access services, primarily through the use of interactive video but also role playing. ${ }^{7}$ It has all 10 characteristics Kirby identified as necessary for effective programmes. ${ }^{9}$ The exercises were developed specifically for the programme or modified from other packs. ${ }^{17}$

\section{Conventional education}

In the 12 control schools sex education for third and fourth years varied from seven to 12 lessons in total, primarily devoted to provision of information and discussion. Only two control schools routinely demonstrated how to handle condoms, and none systematically developed negotiation skills for sexual encounters. The cost of conventional education varied, with individual packages starting from about $£ 20$. Few teachers had more than one day's training, which would have cost about $£ 180$ a day, and some had received none or only a few hours' training.

\section{Recruitment and randomisation of schools}

We invited all non-Roman Catholic state schools within 15 miles of the main cities in Tayside and Lothian regions to participate (figure). Roman Catholic schools were not included as the feasibility study showed that they would not agree to deliver the programme as it takes a harm reduction approach, encouraging those who have sex to use condoms.

Incentives offered were the full cost of the teacher training, including supply cover, or, for schools allocated to the control arm, the equivalent (£2000-£2500) to spend on personal and social education (PSE) but not on sex education. A balanced randomisation took into account socioeconomic characteristics of the school populations, the proportion of pupils staying at school beyond the age of 16 , school size, and local sexual health services, among other factors. ${ }^{19}$ One of these was the quality of school sex education before the trial, a measure that included levels of teacher training.
We calculated the sample size to have $80 \%$ power to detect a $33 \%$ decrease in the cumulative termination rate (identified as the main outcome) from after the delivery of the programme in intervention schools to age 20 with a two sided $t$ test. A design effect of 1.5 was assumed.

\section{Follow-up data and statistical analysis}

The information services division (ISD) of the NHS in Scotland holds data on all births, stillbirths, miscarriages, and terminations in Scotland. ${ }^{2}$ We submitted records of surname, forename, date of birth, and postcode(s) for the women in the trial (excluding withdrawals) for linkage to the NHS data. The division provided the results of the linkage to researchers in aggregate form, as per the requirements of their privacy advisory committee. The data were aggregated by school, cohort, status as early or late school leaver (leaving school at the minimum age legally allowed (16 years) or staying on later), and parents' socioeconomic status (manual $v$ non-manual workers) only for those who stayed on at school. Confidentiality constraints did not allow further disaggregation. These selections were informed by our previous work, which had shown them to be powerful predictors of self reported sexual behaviour. ${ }^{20}$ The division also provided aggregated data on the ages at conception for all linked events.

We submitted records for 4196 women (2109 from the first cohort and 2087 from the second) to the division, and 922 (22\%) linked to one or more conceptions with an estimated date between the pupils' 15th and 20th birthdays. By their 15th birthday, most pupils had received the first year of the programme and at least a proportion had received the second year. If we had chosen age 16 as the start date (with complete delivery of the programme) then some of the conceptions and terminations after the programme would have been missed. The ideal cut-off age would have been $15^{\circ} 5$ years but that was not possible because of the linkage requirements. The results were the same

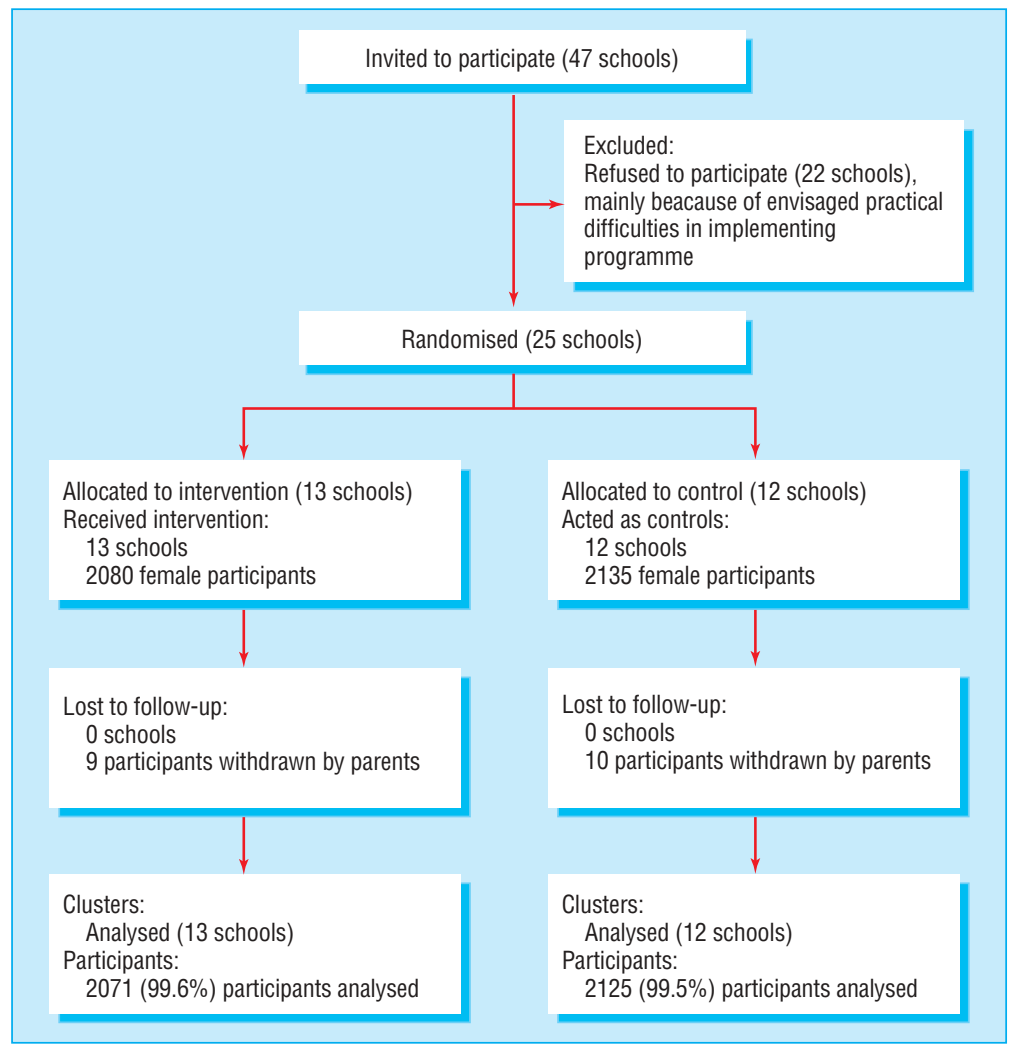

Flow of clusters and female participants through the trial 
Table 1 Characteristics of schools and female pupils according to allocation to teacher delivered sex education (SHARE) or existing sex education (control). Figures are numbers (percentages) of pupils unless stated otherwise

\begin{tabular}{lcc} 
& SHARE & Control \\
\hline No of schools & 13 & 12 \\
\hline Mean (range) socioeconomic factor & $0.1(-2.9-4.8)$ & $-0.2(-2.8-2.8)$ \\
\hline Mean (range) No of women/school & $163.5(57-259)$ & $172.6(112-259)$ \\
\hline No of pupils & 2125 & 2071 \\
\hline No in cohort 1 & $1069(50)$ & $1018(49)$ \\
\hline No in cohort 2 & $1056(50)$ & $1053(51)$ \\
\hline School leaver status and social class: & & \\
\hline Early leavers & $531(25)$ & $546(26)$ \\
\hline $\begin{array}{l}\text { Late leavers, parents with manual } \\
\text { occupations }\end{array}$ & $855(40)$ & $776(38)$ \\
\hline $\begin{array}{l}\text { Late leavers, parents with non-manual } \\
\text { occupations }\end{array}$ & $739(36)$ & $749(36)$ \\
\hline
\end{tabular}

when we used an age of 16 as the start date (data not shown). A few events may have been missed when conceptions or terminations were not registered in Scotland, though this should affect both arms of the trial equally.

To be able to assess the impact of deprivation at school level and to adjust for it in the analysis, we developed a school level socioeconomic measure based on several of the school level indicators used to balance the randomisation at baseline. We used factor analysis to weight the Carstairs' deprivation category $^{21}$ and the unemployment rate for the schools' catchment areas, staying on rates to S5 (at age 15-16) and S6 (at age 16-17), percentage of school leavers unemployed or on government training schemes, percentage of pupils claiming free school meals, and rates of school attendance. Each indicator contributed in approximately equal proportions to the final measure, which was scaled to a mean of zero and a standard deviation of one, with high scores indicating a more deprived school.

Rates of conceptions and terminations were calculated from the events identified at linkage. We used a restricted randomisation test ${ }^{22}$ that allows for the balance imposed by the design to compare the rates between the programme and control arms of the trial. Analyses were adjusted for the individual factors (school leaver status and social class) and the socioeconomic factor at school level. Further model based analyses of the two binary outcomes (any conception and any abortion) were carried out with the SAS GLIMMIX procedure to compute design effects and intracluster correlations.

\section{Results}

We have previously shown that the schools were well balanced on characteristics of individual pupils at baseline. ${ }^{14}$ At age 14, the sample was representative of young people in Scotland in terms of socioeconomic status and family structure according to the 1991 census. ${ }^{20}$ Table 1 shows characteristics of schools and pupils for women only.

The overall observed rates of 287 per 1000 for conceptions and 119 per 1000 for terminations compare with figures for all Scotland of 319 per 1000 for conceptions and 127 per 1000 for terminations for the same age group over the same time span.

There were large differences in rates of conceptions and terminations between the schools. The termination rate did not follow the same pattern as the conception rate: the proportion of conceptions terminated was higher for those schools with low overall conception rates. The conception rate was strongly
Table 2 Rates of terminations and conceptions in teenagers per 1000 pupils and rates of any termination and conception per 1000 pupils* according to allocation to teacher delivered sex education (SHARE) or existing sex education (control). $†$ Figures are differences between SHARE minus control with $95 \%$ confidence intervals and $P$ valuesł

\begin{tabular}{|c|c|c|c|c|}
\hline & $\begin{array}{c}\text { Termination } \\
\text { rate/1000 }\end{array}$ & $\begin{array}{c}\text { Conception } \\
\text { rate/1000 }\end{array}$ & $\begin{array}{c}\text { Any } \\
\text { termination/ } \\
1000 \text { women }\end{array}$ & $\begin{array}{c}\text { Any } \\
\text { conception/1000 } \\
\text { women }\end{array}$ \\
\hline $\begin{array}{l}\text { SHARE schools } \\
(n=2125)\end{array}$ & 126.6 & 300.2 & 108.9 & 222.6 \\
\hline $\begin{array}{l}\text { Control schools } \\
(n=2071)\end{array}$ & 112.0 & 273.8 & 104.3 & 216.8 \\
\hline Unadjusted & $\begin{array}{c}14.6 \\
(-13.1 \text { to } 42.2) \\
P=0.32\end{array}$ & $\begin{array}{c}26.4 \\
(-33.3 \text { to } 86.2) \\
P=0.40\end{array}$ & $\begin{array}{c}45 \\
(-18.0 \text { to } 27.0) \\
P=0.71\end{array}$ & $\begin{array}{c}5.7 \\
(-34.2 \text { to } 45.0), \\
P=0.87\end{array}$ \\
\hline $\begin{array}{l}\text { Adjusted for } \\
\text { school } \\
\text { socioeconomic } \\
\text { measure }\end{array}$ & $\begin{array}{c}15.3 \\
(-11.5 \text { to } 42.2) \\
P=0.28\end{array}$ & $\begin{array}{c}30.4 \\
(-12.8 \text { to } 73.6) \\
P=0.18\end{array}$ & $\begin{array}{c}5{ }^{\circ} 1 \\
(-17.1 \text { to } 27.3) \\
P=0.67\end{array}$ & $\begin{array}{c}15.3 \\
(-20.5 \text { to } 37.2), \\
P=0.57\end{array}$ \\
\hline $\begin{array}{l}\text { Adjusted for } \\
\text { school } \\
\text { socioeconomic } \\
\text { measure and } \\
\text { leaver/social } \\
\text { class measure }\end{array}$ & $\begin{array}{c}15.7 \\
(-10.7 \text { to } 42.1), \\
P=0.26\end{array}$ & $\begin{array}{c}31.9 \\
(-16.1 \text { to } 79.9) \\
P=0.22\end{array}$ & $\begin{array}{c}5^{\circ} 6 \\
(-16.0 \text { to } 27.2) \\
P=0.67\end{array}$ & $\begin{array}{c}9.7 \\
(-21.8 \text { to } 41.2), \\
P=0.54\end{array}$ \\
\hline
\end{tabular}

*Includes live births, stillbirths, therapeutic terminations, and miscarriages.

†Some pupils have $\geq 1$ termination/conception. "Termination rate per 1000" and "conception rate per 1000" show rates for terminations and conceptions even when some of these events belong to same woman. "Any termination per 1000 women" and "any conceptions per 1000 woman" show rates for "any" women experiencing these events.

$\ddagger$ Restricted randomisation test, two sided.

related to socioeconomic factors, whereas the relation between socioeconomic factors and terminations was somewhat weaker.

Table 2 shows that SHARE pupils had slightly higher rates of conceptions and terminations than the control pupils, but differences were not significant. The model based analyses for the binary outcomes confirmed the lack of evidence of differences by treatment arm. Approximate intracluster correlations ${ }^{23}$ were 0.04 for any conception and 0.005 for any abortion, corresponding to design effects of 8 and 2, respectively. After adjustment for covariates the correlations were reduced to 0.003 and 0.002 , both yielding design effects under 1.5.

\section{Discussion}

This rigorous evaluation of a sex education programme delivered by teachers did not find any benefit on rates for conception or termination compared with normal sex education. A balanced randomisation ensured optimal matching of control and intervention arms, and linkage to NHS data on conceptions and terminations ensured no reporting bias and only minimal attrition from the original eligible sample. This is in contrast to the $60 \%$ attrition in the sample when followed up by postal questionnaire to age 20 . In the current study, there may have been a small level of attrition across both arms because of women attending private health care (less than $2 \%$ of terminations), moving from Scotland during the study period ( $1 \%$ average annual migration out of Scotland), or having their terminations in England or Wales (2.7\% of all the terminations performed on Scottish residents) ${ }^{24-26}$ On balance, the comparison between this study and national rates suggests that the linkage was broadly effective.

We followed up all the girls in the sample to the age of 20 (4.5 years after the intervention) and found no significant differences between the two groups in levels of conceptions and terminations. Though by the age of 20 some of the conceptions may have been planned, to have adequate statistical power we had to include conceptions until each girl's 20th birthday. 
Furthermore, there is no reason to assume that planned pregnancies would not be balanced across both arms of the trial. Further analysis (not presented) indicated that these results cannot be explained by differential quality of delivery of the programme. The observed lack of impact on the primary sexual outcomes is in keeping with results of several other rigorous evaluations of school sex education ${ }^{12}$ but not all. ${ }^{27}$ There were large differences in rates of conceptions and terminations between schools. The strong relation between conceptions and social deprivation, and the inverse relation between rate of conceptions and proportion of those conceptions that were terminated, mirror findings for the United Kingdom as a whole. ${ }^{2}$

Overall, the findings suggest that an enhanced programme, which included the 10 characteristics previously suggested to be important, ${ }^{9}$ was no more effective than conventional provision in overcoming the strong socioeconomic and cultural influences that shape rates of conception and termination. As with most trials of school sex education in developed countries, we compared this programme with conventional sex education rather than nothing at all, and conventional sex education may have an important impact on limiting unwanted conceptions.

We have previously published interim outcomes from this study, based on self reported data from both boys and girls at median age 16 years 1 month (six months after the intervention), when only a third of the sample had reported having had sexual intercourse. ${ }^{14}$ At this age, pupils and teachers preferred the SHARE programme compared with conventional sex education. It also increased pupils' practical knowledge of sexual health, reduced regret of first sexual intercourse with most recent partner (all significant), and had small but significant beneficial effects on beliefs about alternatives to sexual intercourse and intentions to resist unwanted sexual activities and to discuss condoms with partners. ${ }^{14}{ }^{15}$ These results contributed to the Scottish Executive's decision to continue to use the SHARE programme in Scottish schools. ${ }^{28}$ The programme did not, however, affect reported sexual experience or use of contraception. ${ }^{14}$

A cluster randomised trial of pupil led sex education compared with conventional teacher led sex education in England (RIPPLE study) was conducted over a similar time period to our study and collected similar, but only self reported, outcomes. The RIPPLE study found that by the age of 16 , significantly fewer girls in the peer led group reported having intercourse compared with the conventional education group (35\% v 41\%), but proportions were similar for boys (33\% v 31\%). The proportions of pupils reporting unprotected first sexual intercourse did not differ for girls or boys. ${ }^{29}$ While the results of the RIPPLE study were broadly positive, they are all based on self reports and the size of the effects on behaviour were modest.

The potential for whole class sex education delivered by teachers to influence young people's behaviour might have already been reached by conventional provision. To have a stronger impact on the sexual health outcomes for young people, complementary interventions should be considered. The social patterning of conceptions and terminations, evident from the variations between schools in this study, suggests that effective programmes have to address fundamental socioeconomic divisions in society, while the influence of parenting factors on sexual experience ${ }^{30}{ }^{31}$ points to strategies involving parents. To date, the most promising programmes have greater scope and duration than school sex education and aim to change future life opportunities for young people..$^{92}$

We thank the young people and teachers involved for their cooperation and support, without which the study would not have been possible; Rod Muir, Alan Finlayson, and David Clark of the information and statistics division of
NHS Scotland for providing data and support; Douglas Kirby for advice; our advisory committee and colleagues in the MRC Social and Public Health Sciences Unit and Applied Statistics Group, Napier University, for advice and encouragement; and Sally Macintyre for helping with the study design and support.

Contributors: DW (principal investigator) and SS originated the study. DW, GMR, SS, CA, and GH designed the original study, while MH, GMR and DW collaborated with the NHS Scotland to access the data, which was analysed by GMR and MH and commented on by DW, CA, and AP. MH, GMR, and DW drafted the paper and $\mathrm{MH}$ revised subsequent drafts based on coauthors' comments. GMR, CA, AP, GH, DW, and SS commented on subsequent drafts of the paper and agreed on the final version. MH, GMR, and DW are guarantors.

Funding: UK Medical Research Council and the Health Education Board for Scotland.

Competing interests: None declared.

Ethical approval: Glasgow University's ethical committee for non-clinical research involving human subjects. NHS Scotland's privacy advisory committee.

Singh S, Darroch JE. Adolescent pregnancy and childbearing: levels and trends in industrialized countries. Fam Plann Perspect 2000;32:14-23.

2 Social Exclusion Unit. Teenage pregnancy. London: Stationery Office, 1999 (4342) www.socialexclusion.gov.uk/downloaddoc.asp?id $=69$.

3 Wight D, Henderson M, Raab G, Abraham C, Buston K, Scott S, et al. Extent of regretted sexual intercourse among young teenagers in Scotland: a cross sectional survey. BMJ 2000;320:1243-4.

4 Watts C, Zimmermann C. Violence against women: global scope and magnitude. Lancet 2002;359:1232-7.

5 Diamond I, Clements S, Stone N, Ingham R. Spatial variation in teenage conceptions in south and west England. JR Stat Soc Ser A Stat Soc 1999;162:273-89.

6 NHS Centre for Reviews and Dissemination. Preventing and reducing the adverse effects of unintended teenage pregnancies. York: NHS Centre for Reviews and Dissemination, 1997.

7 Abraham C, Wight D, Scott S. Developing the SHARE sex education programme: from theory to classroom implementation. In: Rutter D, Quine L, eds. Changing health behaviour: research and practice with social cognition models. Maidenhead: Open University Press, 2001.

8 Gallant M, Maticka-Tyndale E. School-based HIV prevention programmes for African youth. Soc Sci Med 2004;58:1337-51.

9 Kirby D. Effective approaches to reducing adolescent unprotected sex, pregnancy and childbearing. J Sex Res 2002;39:51-7.

10 Robin L, Dittus P, Whitaker D, Crosby R, Ethier K, Mezoff J, et al. Behavioral interventions to reduce incidence of HIV, STD, and pregnancy among adolescents: a decade in review. J Adolesc Health 2004;34:3-26.

11 Guyatt GH, DiCenso A, Farewell V, Willan A, Griffith L. Randomized trials versus observational studies in adolescent pregnancy prevention. J Clin Epidemiol 2000;53:167-74.

12 DiCenso A, Guyatt G, Willan A, Griffith L. Interventions to reduce unintended pregnancies among adolescents: systematic review of randomised controlled trials. BMJ 2002;324:1426-30.

13 Cabezon C, Vigil P, Rojas L, Leiva ME, Riquelme R, Aranda W, et al. Adolescent pregnancy prevention: an abstinence-centered randomized controlled intervention in a Chilean public high school. J Adolesc Health 2005;36:64-9.

14 Wight D, Raab G, Henderson M, Abraham C, Buston K, Hart G, et al. The limits of teacher-delivered sex education: interim behavioural outcomes from a randomised trial. BMJ 2002;324:1430-3.

\section{What is already known on this topic}

Overviews have suggested that sex education delivered by teachers can delay age at first sexual intercourse and reduce unsafe or unprotected intercourse

More rigorous evaluations, however, generally have less positive outcomes and, to date, few evaluations have used objective measures of sexual risk taking

\section{What this study adds}

Enhanced sex education (SHARE) improved knowledge and reduced regret but did not reduce conceptions or terminations compared with conventional sex education

High quality sex education should be continued, but to reduce unwanted pregnancies complementary, longer term interventions that address socioeconomic inequalities and the influence of parents should be developed and rigorously evaluated 
15 Abraham C, Henderson M, Der G. Cognitive impact of a research-based school sex education programme. Psychol Health 2004;19;689-703.

16 Wight D, Abraham C. From psycho-social theory to sustainable classroom practice: developing a research-based teacher-delivered sex education programme. Health Educ Res 2000;15:25-38.

17 Wight D, Dixon H. SHARE: the rationale, principles and content of a research-based teacher-led sex education programme. Educ Health 2004;22:3-7.

18 Wight D, Abraham C, Scott S. Towards a psycho-social theoretical framework for sexual health promotion. Health Education Research 1998;13:317-30.

19 Raab G, Butcher I. Balance in cluster randomized trials. Stat Med 2001:20:351-65.

20 Henderson M, Wight D, Raab G, Abraham C, Buston K, Hart G, et al. Heterosexual risk behaviour among young teenagers in Scotland.J Adolesc 2002;25:483-94.

21 McLoone P. Carstairs scores for Scottish postcode sectors from 2001 census. Glasgow: MRC Social and Public Health Sciences Unit, 2004. www.msoc-mrc.gla.ac.uk/Publications/ pub/PDFs/PHRU/Carstairs.pdf.

22 Raab GM, Butcher I. Randomization inference for balanced cluster-randomized trials. Clin Trials 2005;2:130-40.

23 Goldstein H, Browne WJ, Rasbash J. Partitioning variation in multilevel models. Understanding Statistics 2002;1:223-32.

24 ISD Scotland. Scottish health statistics: (terminations of pregnancy) abortions performed in Scotland. www.isdscotland.org/isd/1916.html.

25 Information and Statistics Division. Abortion statistics 1998- ISD Scotland Health Briefing. Edinburgh: ISD, 1999.

26 General Register Office for Scotland. Scotland's census 2001-statistics on migration. www.gro-scotland.gov.uk/statistics/library/occpapers/scotlands-census-2001statistics-on-migration/index.html.

27 Coyle K, Basen-Engquist K, Kirby D, Parcel G, Banspach S, Collins J, et al. Safer choices: Reducing teen pregnancy, HIV, and STDs. Public Health Rep 2001;116:82-93.

28 Scottish Executive. Respect and responsibility: strategy and action plan for improving sexual health. Edinburgh: Scottish Executive, 2005.

29 Stephenson JM, Strange V, Forrest S, Oakley PA, Copas A, Allen E, et al. Pupil-led sex education in England (RIPPLE study): cluster-randomised intervention trial. Lancet 2004;364:338-46
30 Wight D, Williamson L, Henderson M. Parental influences on young people's sexual behaviour: a longitudinal analysis. J Adolesc 2006;29:473-94.

31 Santelli JS, Lowry R, Brener ND, Robin L. The association of sexual behaviors with socioeconomic status, family structure, and race/ethnicity among US adolescents. Am J Public Health 2000;90:1582-8.

32 Philliber S, Kaye J, Herrling S, West E. Preventing pregnancy and improving health care access among teenagers: an evaluation of the Children's Aid Society-Carrera programme. Perspec Sex Reprod Health 2002;34:244-51.

(Accepted 6 October 2006)

doi $10.1136 /$ bmj. .39014 .503692 .55

Medical Research Council Social and Public Health Sciences Unit, Glasgow G12 8RZ

M Henderson research scientist

D Wight programme leader

A Parkes research associate

School of Nursing Midwifery and Social Care, Napier University, Edinburgh EH4 2LD

G M Raab professor

School of Social Sciences, University of Sussex, Brighton BN1 9SN

C Abraham professor

Faculty of Humanities and Social Sciences, University of Keele, Keele ST5 5BG $\mathrm{S}$ Scott professor

Centre for Sexual Health and HIV Research, University College London, London WC1E 6AU

$\mathrm{G}$ Hart director

Correspondence to: M Henderson marion@msoc.mrc.gla.ac.uk 